\title{
3D Printed Surgical Guides Used in Orthodontics
}

\begin{abstract}
CAMELIA SZUHANEK ${ }^{1}$, ANA MARIA MIHAI ${ }^{2 *}$, ADINA SARBU2, MARIUS PRICOP 1
${ }^{1}$ Victor Babes University of Medicine and Pharmacy, Faculty of Dentistry, 2 Eftimie Murgu Sq., 300041Timisoara, Romania 2Iuliu Hatieganu University of Medicine and Pharmacy, Faculty of Dentistry, 8 Victor Babes Str., 400012, Cluj Napoca, Romania

With technology becoming more and more advanced, the medical system is being consistently improved. From intraoral scanners that started to replace conventionally impressions technique to printed surgical guides that directs the drilling systems of implants, dentistry is one of the beneficiars of new and advanced treatments that are ergonomic, safe and put both the medical team and the patient in a more pleasant experience. The purpose of our article is to summarize the application of acrylic and metacrylic resin in 3D printing of surgical guides used in orthodontics.
\end{abstract}

Keywords: technology, advanced treatments, intraoral scanner, printed surgical guides.

Though acrylic resin is known to product alergic reactions, it is a common material used in dentistry as base for dentures or orthodontic removable appliances, temporary crowns [9] and lately for 3D printing. In the additive manufacturing technique (3D printing), there is not a wide range of materials to choose and among metallic and ceramic materials, acrylic resin is the most processed [10].

Recent studies reveal that if printed and lightcured, the resin used in surgical guides reduces the negative impact on L929 Cell and on human gingival fibroblasts [11]. This information is of clinical importance in producing surgical guides, since they can be either supported by bone, by the mucosa or by the teeth[2].

$3 \mathrm{D}$ printing in orthodontics is used beside fabrication of study models, clear aligner models, in producing drilling templates, pilot drill guides, surgical guides[13] for inserting miniimplants, custom-made appliances like clear aligners, lingual appliances, wires[12,14] splints and occlusal guards[13].

Regarding surgical guides, they don't only help the surgeon to insert the implants, but are also reliable, safe and when used, the surgery is minimally invasive, giving the patient a better after surgery recovery experience[1]. They have been recently used also for teeth autotransplantation, guided osteotomy and root resection[11].

As stated before, present studies reveal the use of surgical guides not only for dental implant insertion, but also in orthodontic miniimplants placement. Being autoclavable and biocompatible[13], the resin used in 3D printed surgical guides came to help the practician and to fulfill a wide range of needs.

The template for the surgical guide be made either using a customized conventional Rx surgical method or a computer generated one. Besides the stiffness and the instability given by the template made using conventional Rx surgical method, it also has some limitations that one cannot overlook, the most important ones being the lack of information given for the bucco-lingual dimension and for the anatomical landmarks[2].

For achieving stability of the surgical guide during implant placement, retention criteria has to be reached. This way, they provide enough accuracy for placing the implants as previously established on the digital setup with no damage to the surrounding anatomical landmarks, this way increasing the success rate of the miniscrews[4].

Recently, surgical guides have been used also for piezoelectric corticotomy, having special material characteristics like higher porosity for the coolant, translucency to provide visibility and rigidity for support[3]. In placing C-tube miniplates, printed surgical guides have shown their effectiveness, minimizing the lab work and the high awareness demanded by the conventional technique[ 8].

In order to create an implantsurgery guide the practician needs computer tomography, 3D implant planning software and image guided template production technique[2]. The CBCT is indicated due to the low radion and high resolution in all three dimensions[7].

\section{Experimental part}

Matherials and methods

The first step in obtaining a surgical guide is providing data record from the patient. Besides intraoral and extraoral photographs and intraoral scanning, that will provide a virtual cast, a Cone Beam Computer Tomography is required. After the evaluation of the available bone areas in transverse and axial incidence, the digital setup of the future position of the miniscrews is being made. This setup can be either made by the medical doctor or by the technician and in the end sent to the medical practice for the doctors' approval.

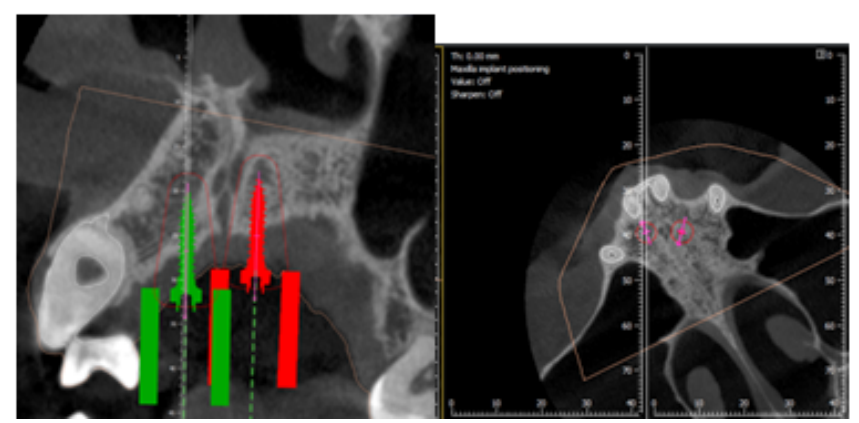

Fig.1. Palatal implant digital planning - transversal and axial view.

Careful assessment needs to be done before setting up the implants for excluding the possibility of dental complications. 


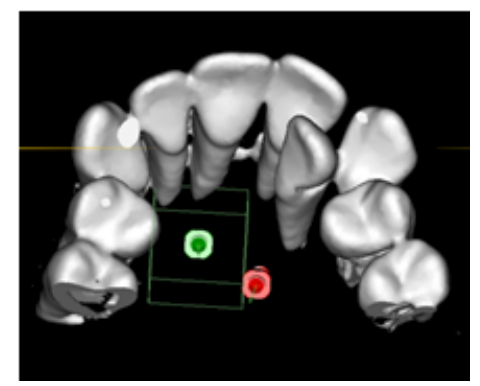

Fig.2. Adaptation of the model with the CBCT

After the radiographic setup of the miniscrew placement, a visualization on the 3D digital model is needed for selecting the positions of the guiding cylinders.

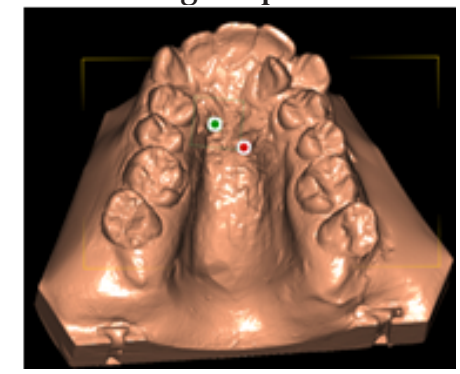

Fig. 3. Final implant position on the digital cast.

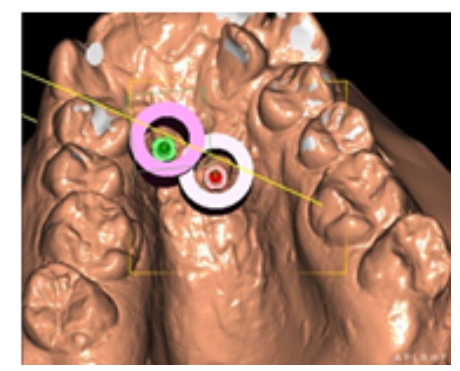

Fig. 4. Digital setup of the surgical guiding cylinders on virtual model.
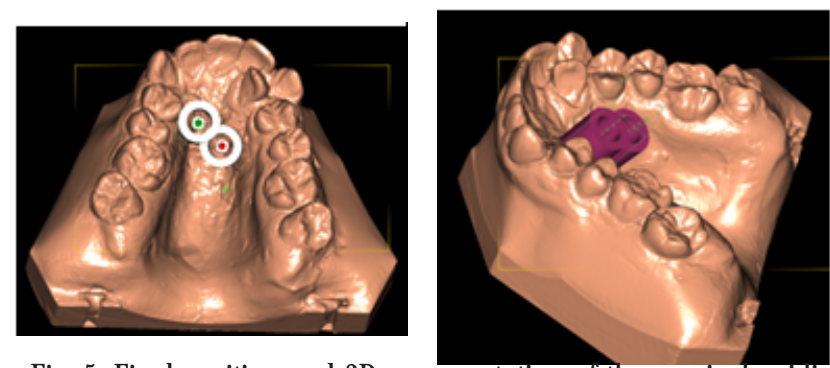

Fig. 5. Final position and 3D representation of the surgical guiding cylinders .

Once the lab setup is accepted by the medical doctor, a 3D printed model and surgical guide are manufactured. On the printed cast, the hybrid expander will be realized.

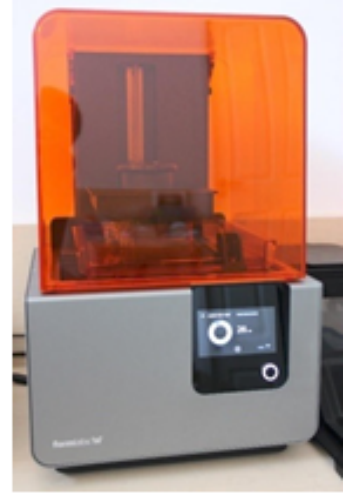

Fig. 6. Formlabs 2 3D Printer

The printing machine and material used for both surgical guide and cast were from Formlabs, Inc.. The resin used for the surgical guide and the cast is made from acrylic and methacrylic acid esters, photoinitiators, proprietary pigmentand additive package. It can change its properties according to the settings of the printer, temperature, print orientation. Another variable in the materials' properties is the obtaining method which can be only washnig and air drying (green resin), or, additionally light cured for an hour(post-cured resin) [5].

The mechanical properties of the light cured resin are $61 \mathrm{MPa}$ tensile strength at yield, 2.7 GPa tensile modulus and $5 \%$ elongation to failure compared to $33 \mathrm{MPa}, 1.6 \mathrm{GPa}$ and $25 \%$ of the green resin.

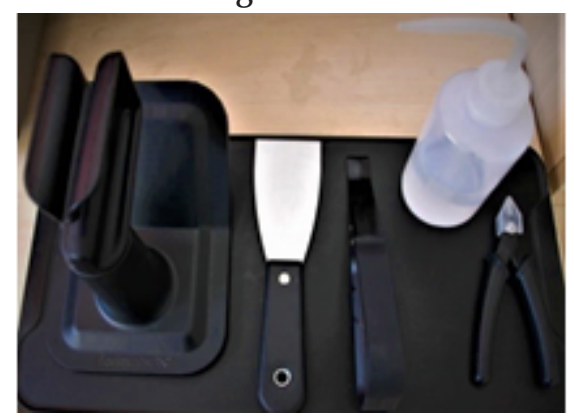

Fig.7. Instruments used for material mixture.

The flexural strenght at 5\% strain is of $95.8 \mathrm{MPa}$ and flexural modulus of $2.5 \mathrm{GPa}$ for the light-cured resin and about $1 / 3$ of these values for the green resin[5].

Both types of resin are resistant to solvents like acetic acid $5 \%$, bleach, $\sim 5 \% \mathrm{NaOCl}$, Hydrogen peroxide $3 \%$, isooctane, Sodium hydroxide $(0.025 \%, p H=10)$, salt water $(3.5 \% \mathrm{NaCl})$ and water[5].

When exposed in solvents like acetone,butyl acetate, diethyl glycol monomethyl ether, isopropyl alcohol and xylene, the green resin will decrease its' mechanical properties while the light cured resin will degradate just under acetone exposure.

Due to its components, the material can cause skin or respiratory irritation. Prevention measures are wearing protecting gloves and avoid inhaling the vapours[5].
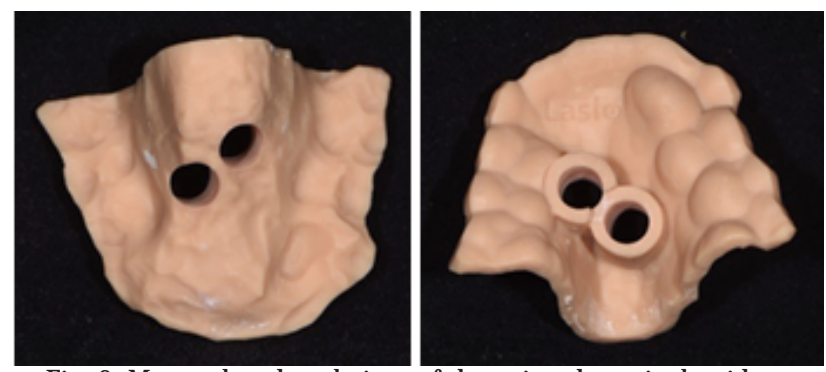

Fig. 8. Mucosal and oral view of the printed surgical guide

In the Easy Driver complete surgical kit, there are sleeves for guiding the drill and the miniimplants, a screwholder, a guiding cap, a cap remover, two drills (a red drill of $1.4 \mathrm{~mm}$ and a grey one of $1.8 \mathrm{~mm}$, a laboratory finger screwdriver and extension of $16 \mathrm{~mm}$.

The basic surgical set consists of guiding sleeves (for both the drill and the miniscrew), a screw holder, a guiding cap and a cap remover and in the and only one drill of $1.4 \mathrm{~mm}$ (red).

The $1.4 \mathrm{~mm}$ drill is for the $2 \mathrm{~mm}$ screw and the grey one is for the $2.3 \mathrm{~mm}$ screw [6].

After receiving the appliance on the printed guide, the screws are removed using the fingerscrew driver. Once the appliance is being checked in the patients' mouth, the surgical guide is inserted and checked too. If the surgical guide does not fit perfectly, it can be correcred using occlusal spray.

Under local anesthesia, if there is a need for drilling, this procedure will precede the miniimplant placement and will be planned during the digital setup using the drilling sleeve inserted in the surgical guide. Only one sleeve will be inserted at a time both for the drilling and for the insertion stages. Afterwards, the miniimplants are placed using the guiding cap inserted in the cap remover. 


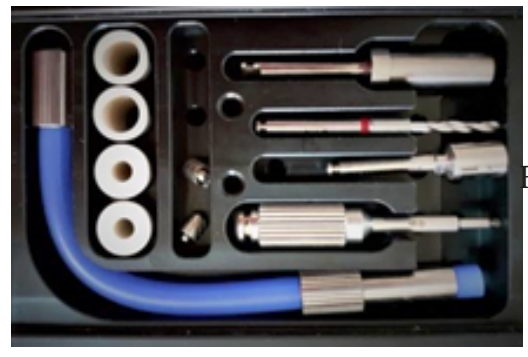

g. 9. Easy Driver surgica Kit for miniimplant insertion.

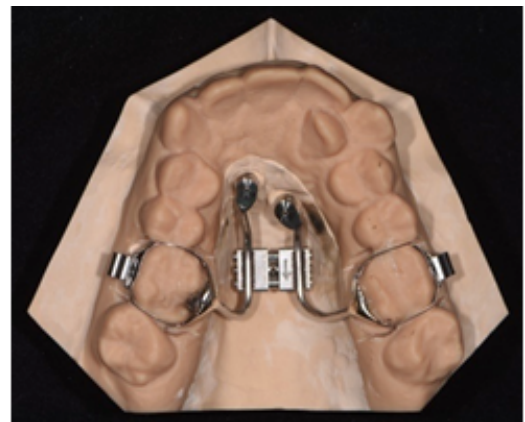

Fig.10. Hybrid maxillary expander attached to the printed cast.

The miniimplant is attached to the guiding cap and the rubber from the cap remover is removed. The miniscrew along with the guiding cap and the screwholder are inserted in the counterangle and throught the miniimplant guiding sleeve that is inserted in the surgical quide, the TAD (temporary anchorage device) is inserted. When the wider part of the screwholder reached the guiding sleeve, the miniimplant is totally inserted.

After insertion of miniimplants, the appliance is settled in place, first fixing screws on the miniimplants and afterwards light curing the cement from the bands.

\section{Results and discussion}

The material used for their fabrication of surgical guides can be either transparent for better visualization or pigmented. They are stiff enough to remain stable during the whole miniimplant placement procedure and for this reason, the clinician can remain calm and confident.

Printed surgical guides have quickly found their way into the orthodontic field, providing an safe and easy method of TAD insertion even for the orthodontists[15-17].

Surgical guides remain a helpful aid in the insertion of orthodontic implants. They are a guarantee for a noninvasive procedure, less pain and swelling after the intervention.

\section{Conclusion}

The materials used in fabrication of printed surgical guides are biocompatible, autoclavable and have specific properties for bringing accuracy and reliability to the medical team.

\section{References}

1.ZNAMIROWSKA-BAJ OWSKA, A., OGINSKI, T., SZELAG, J., Complications During Surgical Insertion of Miniimplants, Dent. Med. Probl. 2011, 48, 1, 11-18.
2.MANIKANDAN RAMASAMY, GIRI, RAMESH RAJA, SUBRAMONIAN, KARTHIK , RACHURI NARENDRAKUMAR, Implant surgical guides: From the past to the present. J Pharm Bioallied Sci. 2013 J un; 5(Suppl 1): S98-S102.

3.HSIN-YU HOU,A CHUNG-HSING LI,B MIN-CHIA CHEN,A PEI-YI LIN,B WEI-CHUNG LIU, YI-WEN CATHY TSAI, REN-YEONG HUANG, A novel 3D-printed computer-assisted piezocision guide for surgically facilitated orthodontics, American Journal of Orthodontics and Dentofacial Orthopedics, April 2019, Vol 155, Issue 4

4.MI-JU BAE,A JI-YOUNG KIM,B JONG-TAE PARK,C JUNG-YUL CHA,D HEE-J IN KIM,E HYUNG-SEOG YU, Chung-J u Hwang, Accuracy of miniscrew surgical guides assessed from cone-beam computed tomography and digital models American Journal of Orthodontics and Dentofacial Orthopedics, J une 2013, Vol 143, Issue 6

5.***Formlabs Material Properties -Dental Model: Photopolymer Resin for Form 2 3D Printers

6.***Easy Driver Prospect- The Guiding System for TADs-Digital Skeletal Anchorage

7.SEONG-HUN KIM, YONG-SUK CHOI, EUI-HWAN HWANG, KYU-RHIM CHUNG, YOON-AH KOOK, GERALD NELSON; Surgical positioning of orthodontic miniimplantswith guides fabricated on modelsreplicated with cone-beam computed tomography; 2007, American Association of Orthodontists. doi:10.1016/j.ajodo.2006.01.027

8.J ANGHYUN PAEK,A DO-MIN JEONG,B YONG KIM,C SEONG-HUN KIM,D KYU-RHIM CHUNG,E AND GERALD NELSON, Virtually fabricated guide for placement of the C-tube miniplate, American Journal of Orthodontics and Dentofacial Orthopedics, May 2014, Vol 145, Issue 5 9.HAROON RASHID, ZEESHAN SHEIKH, FAHIM VOHRA, Allergic effects of the residual monomer used in denture base acrylic resins, Eur J Dent. 2015 Oct-Dec; 9(4): 614-619.

10.SIMONE LANTEAN 1, IGNAZIO ROPPOLO 1,2 ID , MARCO SANGERMANO 1ID, CANDIDO FABRIZIO PIRRI, ANNALISA CHIAPPONE, Development of New Hybrid Acrylic/Epoxy DLP-3D Printable Materials, Inventions 2018, 3, 29.

11.CHRISTOPH KURZMANN, KLARA J ANJ IT, HASSAN SHOKOOHITABRIZI, MICHAEL EDELMAYER, MANUELA PENSCH, ANDREAS MORITZ, HERMANN AGIS, Evaluation of Resins for Stereolithographic 3D-Printed Surgical Guides: The Response of L929 Cells and Human Gingival Fibroblasts, BioMed Research International Volume 2017, Article ID 4057612, 11 pages.

12.SHAHNAZ MAHAMOOD, MAIMOONA ABDUL KHADER, HASHIM ALI, Applications of 3-D Printing in Orthodontics: A Review, International J ournal of Scientifi c Study| February 2016 | Vol 3| Issue 11, Pag:267270.

13.***High-Accuracy 3D Printing Materials for Dental Labs and Practices -Formlabs https://formlabs.com/materials/dental/ Accessed 21 September 2019.

14.K. HERO BREUNING, CHUNG H. KAU, Digital Planning and Custom Orthodontic Treatment, 2017 JohnWiley $\&$ Sons, Inc.

15.SIRBU, A., BORDEA, R., LUCACIU, O.,BRAITORU, C., SZUHANEK, C., CAMPIAN, R.S., 3D Printed Splints an Innovative Method to Treat Temporomandibular J ointPathology, Rev.Chim.Bucharest),69, no. 11, 2018, p. 3087-3089

16.POPA,A., SZUHANEK, C., BRAD, S., Accurate Determination for Orthodontic Mini-implant Placement Using Acrylic Resin Surgical Guide and CBCT. Mat.Plast., 53, no. 2, 2016, p.287

17.DAVID, O.T., SZUHANEK, C., TUCE, R.A., DAVID, A.P., LERETTER, M., Polylactic Acid 3D Printed Drill Guide for Dental Implants Using CBCT, Rev.Chim.(Bucharest), 68, no. 2, 2017, p.341

$\overline{\text { Manuscript received:26.06.2019 }}$ 